\title{
ANÁLISE DO ACESSO À INTERNET NAS UNIDADES DA FEDERAÇÃO DO BRASIL: ELEMENTOS PARA O PLANEJAMENTO TERRITORIAL
}

\author{
Vandeir Robson da Silva Matias \\ Professor Centro Federal de Educação Tecnológica de Minas Gerais - CEFET MG \\ vandeir@cefetmg.br
}

\section{Resumo}

O planejamento territorial é um instrumento para organizar e ordenar o território brasileiro, harmonizando as relações econômicas, sociais e ambientais que nele acontecem. Para que ocorra sua eficácia, é necessário um efetivo esforço de compartilhamento institucional, voltado para a integração das ações e políticas públicas territoriais, bem como articulação com a sociedade civil, congregando seus interesses em torno de um pacto pela gestão do território. O uso da internet pode promover o acesso à informação e uma maior integração na sociedade. Parte significativa da prestação de serviços municipais, estaduais e federais já ocorre com aporte da rede de computadores de alguma forma. O objetivo geral desse artigo é realizar uma análise espacial do uso e acesso à internet pelas Unidades da Federação no Brasil a partir do aporte da técnica de análise de cluster. O objetivo específico é realizar a partição ideal, ou seja, identificar os grupos formados para subsidiar políticas públicas específicas para cada grupo formado. Foram selecionadas dez variáveis e os dados foram tratados a partir do software estatístico MiniTAB. Ao final, chegou-se a formação de nove clusters. A análise de cluster foi essencial para a criação de grupos e definição dos perfis. A separação das Unidades da Federação em conglomerados foi viável para conseguir agrupar estados similares entre si e divergentes em relação aos outros grupos que precisam de políticas públicas diferentes para fomentar a ampliação do acesso à internet no Brasil.

Palavras-chave: Estatística multivariada. Análise de dados. Planejamento territorial. Internet.

\section{ANALYSIS OF INTERNET ACCESS IN UNITS OF THE BRAZILIAN FEDERATION: ELEMENTS FOR TERRITORIAL PLANNING}

\begin{abstract}
The Territorial Planning is a tool instrument to organize and sort the Brazilian territory, harmonizing and economic relations, social and environmental. Why occurs your efficiency and required has effective institutional sharing effort, aimed paragraph Integration of territorial actions and public policies, as well as articulation with civil society, congregating interests around hum Pact for Land Management. Use the internet can promote access to information and greater integration in society. A significant part of the Provision of Municipal Services, State and Federal, occurs contribution of Computer Network Some form. The General Purpose this artiche and perform a spatial analysis to use and access the internet by Federative Units in Brazil From the multivariate statistical contribution. The Specific
\end{abstract}


Objective and make an ideal partition, identify the groups formed paragraph subsidize specific public policy paragraph each elaborate group. Were selected twelve variables and he data were Treaties from Minitab Statistical Software to version 17. Training the end of the clusters come to nine. Cluster analysis was essential to the creation of groups and definition of profiles. Separation of the Federative Units in clusters was feasible paragraph getting group states similar and divergent in relation to others that groups need public policies different paragraph fostering Internet access expansion in Brazil.

Keywords: Multivariate statistics. Data analysis. Territorial planning. Internet.

\section{Introdução}

As tecnologias digitais da informação e comunicação (TDIC) já fazem parte do cotidiano na população em várias atividades como lazer, trabalho, educação, mobilização social, participação política, entre outros. O Instituto Brasileiro de Geografia e Estatística (IBGE) define como TDICs: internet, rádio, televisão, microcomputador, telefone fixo, telefone móvel, antena parabólica, televisão a cabo, fax, câmeras digitais, tablets, entre outras.

A internet, em especial, se dissemina no país desde a década de noventa do século passado e verifica-se que grande parte da sociedade utiliza essa tecnologia alguma parte do dia. O uso da internet pode promover o acesso à informação e uma maior integração do indivíduo na sociedade. Parte significativa da prestação de serviços municipais, por exemplo, já ocorre com aporte da rede de computadores de alguma forma. Assim, quanto maior o acesso da população e conhecimento para utilizar essa ferramenta, maior a promoção de cidadania e participação popular na gestão do espaço urbano (MATIAS, 2011).

Percebe-se que os avanços nos setores de telecomunicações geram um impulso de um enorme fluxo de informações, que passam a ser processadas e difundidas numa velocidade cada vez maior. Por conseguinte, observa-se o incremento das TDIC e um espaço cibernético em constante ampliação. Como a internet não está disseminada em todo o território nacional, apenas parte da sociedade utiliza essa tecnologia para interagir com o poder público. Essa interação configura um espaço público diferente, que ainda pode se tornar um ciberespaço voltado para os exercícios do lazer, experimentação, cidadania e democracia.

O acesso à Internet influencia no desenvolvimento sociocultural da população, pois se trata de um fluxo enorme de informações que divulgam ideias, comportamentos e culturas bem diferentes uma das outras. Esse fator pode colaborar para o desenvolvimento da sociedade, que depende da forma que a internet será utilizada, além da forma com que produzirá e disseminará suas informações. 
A partir do seu uso intenso em vários setores, a internet pode resgatar a centralidade da ação humana e o protagonismo das práticas participativas e comunicativas. Contudo, muitas vezes esse processo de informatização social não vem acompanhando da racionalidade e bom senso. Os usos da internet experimentados até então estão mais voltados para atividades individuais de lazer do que atividades coletivas e colaborativas para fins de planejamento.

As TDIC viabilizam a comunicação e proporcionam interação e descobertas para os cidadãos. $\mathrm{O}$ uso da internet, por exemplo, permite monitorar os processos eleitorais, gerando um maior accountabillity ${ }^{1}$ contra fraudes eleitorais. Na esfera do executivo, a internet facilita o acesso a informações fiscais e burocráticas, além de possibilitar a fiscalização de obras e consertos agendados pelo poder público.

A Internet possui uma história recente, mas que evoluiu muito rápido, beneficiando, assim, de maneira significativa a globalização e proporcionando um fluxo intenso de informação em alguns territórios em detrimento de outros. A questão central é como este processo se desenvolve e quem participa dele. Utilizar a internet envolve custo com um determinado equipamento (smartphone, tablet, computador de mesa, computador portátil, entre outros) assim com a forma de conexão (banda larga fixa ou móvel, linha telefônica, satélite, entre outras formas). Assim, constata-se que nem toda a sociedade a utilizará em função do seu custo. É necessário traçar o perfil dos usuários da internet para melhorar o seu acesso a partir de políticas públicas adequadas e garantir assim melhores condições de partição e acesso à informação dos habitantes no espaço público. Sabe-se que a disseminação da tecnologia não garante o seu acesso, pois, em várias partes do mundo, um quantitativo considerável não possui nem as condições básicas de saneamento, alimentação, moradia, saúde, entre outros bens caros ao bem estar de qualquer indivíduo.

Portanto, o objetivo do trabalho é realizar uma análise espacial do uso e acesso a internet por Unidades da Federação no Brasil a partir do aporte da técnica de análise de cluster. Os principais objetivos específicos são: buscar a partição próxima do ideal, identificar os grupos formados e Identificar as características de acesso a internet dentro dos grupos.

\section{A Sociedade em Rede e o Uso da Internet no Planejamento Territorial}

O processo de globalização no seu modelo informacional transformou a organização espacial das relações sociais, territoriais e políticas. O advento da tecnologia possibilitou novas formas de ação política associada a diversos atores sociais e políticos no espaço urbano. 
Em grande parte da sociedade mundial, verificamos a incorporação das políticas de comunicação baseadas em sistemas técnicos e em redes. Existe, então, uma virtualização da sociedade que se expande para os diversos modos de vida. A internet faz parte do dia-a-dia dos habitantes das cidades, sobretudo nos grandes centros. Percebe-se então um uso intenso da internet pela sociedade civil e também o uso pelos governos nas suas diferenças esferas (municipal, estadual e federal) e poderes (executivo, legislativo e judiciário), (MATIAS, 2011). Observa-se na Figura 1 a proporção de domicílios com acesso a internet no Brasil.

A Região Sudeste é a que possui a maior proporção de domicílios com acesso à internet no território nacional, seguida da Região Centro-Oeste. Com o menor acesso, destacam-se os domicílios da Região Nordeste. As sociedades contemporâneas mostram formas de desigualdades socioculturais fortemente associadas às desigualdades de natureza econômica e nas condições objetivas de acesso aos bens tecnológicos. (MATIAS, 2011).

A utilização do ambiente virtual pelo Estado configura-se como uma tentativa de aproximação dos cidadãos com a "democracia", no caso uma "ciberdemocracia", ou seja, o Estado usufrui do ciberespaço de modo a aproximar os cidadãos da gestão da metrópole. É pertinente refletir sobre os limites e possibilidades da relação Sujeito/Cidade a partir da utilização da Internet.

Figura 1- Proporção de domicílio com acesso à internet

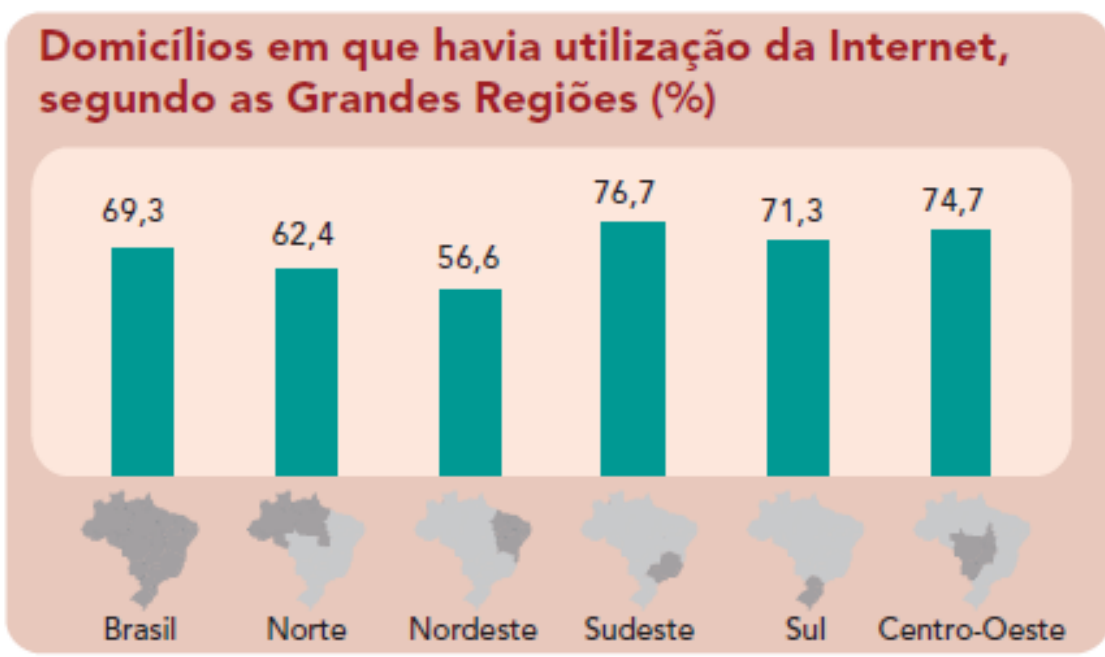

Fonte: IBGE, Diretoria de Pesquisa, Coordenação de Trabalho e Rendimento, Pesquisa Nacional Por Amostra de Domicílios Contínua, 2016.

Assim, é importante o acesso da população à internet, pois cada vez mais os processos da administração pública realizam, consulta pública, disseminação de informação, processos 
deliberativos, etc., através da internet. É pertinente que a população esteja preparada para esse momento. E uma das formas de preparação é o acesso à internet. Nesse sentido, a rede assume funções de reorganização e gerenciamento e apresenta inovações para a sociedade contemporânea (GUIDI, 2002).

O Estado, através de suas ações, compreende que o período atual é da revolução informacional e utiliza a internet em diversas atividades como descrito no gráfico. Divulgação de legislação e prestação de contas são os itens mais recorrentes. Portanto é pertinente, a partir dessa constatação buscar implantar políticas que efetivem a disponibilização de informações e participação para a população.

Existem algumas diferenças do que se entende por democracia e governo eletrônico. O governo eletrônico corresponde ao uso de tecnologias pelos governos como parte do esforço de modernização e racionalização da prestação de serviços públicos aos usuários, melhorando a qualidade dos serviços ofertados, reduzindo custos através do modelo virtual.

O governo avança na política pública do governo eletrônico e cria inclusive processos deliberativos digitais em algumas cidades. Os orçamentos participativos digitais são experiências desse tipo. Para mais informações dessa prática, ver Matias, 2011. Essa é uma forma do governo manter uma interação mais ativa com o usuário do serviço público, ou seja, é um sistema de apoio a decisão.

Os gestores se preocupam substancialmente com a disseminação da informação governamental para dar visibilidade à administração. O Estado cria novas regras do jogo do urbano no contexto das transformações vigentes. É uma nova forma de fazer política, o que configura uma nova forma de analisar o espaço urbano. Dentre as formas de contato e-mail (96\%), fale conosco (85\%) e formulário eletrônico $(78 \%)$ se destacam. O objeto é pedir geral do contato é tirar uma dúvida, fazer uma reclamação ou pedir uma informação. Dentro do contexto de informação governamental para promoção da cidadania e exercício da democracia, o conceito de governo eletrônico² ganha novos contornos.

Uma das características do governo eletrônico é a perspectiva de entrada em cena de atores nos debates sobre o urbano, com impactos importantes nas políticas públicas que tendem a colocar o cidadão, informação e a cidadania como foco central. A democracia eletrônica pode ser entendida como um conjunto de processos democráticos que propiciam a participação cidadã por meio das TDIC. Estas estão relacionadas com questões fundamentais acerca da natureza da governança e processos decisórios relativos ao Estado e a relação deste 
com os cidadãos. $\mathrm{O}$ uso das novas tecnologias representa uma nova fase para a comunicação democrática, uma nova possibilidade para a participação descentralizada. (MAIA, 2002).

$\mathrm{O}$ direito à informação é colocado em pauta pelos novos cenários da política. $\mathrm{O}$ acesso à informação e o direito à comunicação são direitos inalienáveis do ser humano e, por isso, o acesso e a produção devem ser compreendidos como um novo direito humano fundamental, devendo ser respeitado, garantido e promovido pelo Estado.

A gestão política de alguns municípios brasileiros como São Paulo, Salvador Belo Horizonte, Porto Alegre, Curitiba, entre outros, está embasada nas novas tendências e paradigmas da gestão pública contemporânea. Nessa agenda, temos a ideia de governança, eficiência, governo eletrônico, disseminação da informação, transparência, participação e descentralização. Vislumbram-se transformações dos processos espaciais e de redes sociais no contexto global a partir dos sistemas de engenharia virtuais. A economia política da informação produz uma nova espacialidade e possibilita mudanças na concepção do urbano e cidadania. A informação fortalece o papel do cidadão na sociedade contemporânea, empodera e gera conhecimento necessário às práticas democráticas que interferem no planejamento territorial (UHLIR, 2006).

Atualmente a internet é essencial para o planejamento territorial, que é um instrumento para organizar e ordenar o território brasileiro, harmonizando as relações econômicas, sociais e ambientais que nele acontecem, sobretudo nas grandes cidades do país. Para que ocorra sua eficácia, é necessário um efetivo esforço de compartilhamento institucional, voltado para a integração das ações e políticas públicas territoriais, bem como articulação com a sociedade civil, congregando seus interesses em torno de um pacto pela gestão do território.

Verifica-se que, em uma perspectiva histórica, o planejamento territorial não envolve somente o setor econômico ou mesmo a elaboração de programação orçamentária, a partir de um planejamento governamental. O Planejamento também atua no sentido de trazer melhorias realizadas pelo governo e que garantam em certa medida uma qualidade de vida aos cidadãos. Strictu sensu o ato de planejamento pode ser entendido com a elaboração de um plano ou roteiro de ações que passou por dois aspectos principais. O primeiro é de que o planejador é um guia contrapondo ao improviso o outro aspecto é de que o planejamento pode possibilitar uma contabilização das diversas ações a se realizar.

Para romper com essa lógica perversa, as administrações públicas apostam em um modelo estruturado de gerenciamento da tecnologia e da informação, aplicados de maneira 
sistematizada nos processos de gestão participativa, havendo, portanto, a confiança de que esses sistemas podem ser utilizados para tomada de decisão pelos cidadãos. A Figura 2 mostra as formas de participação ofertada pelos órgãos públicos. Dentre elas destacam as enquetes (18\%) e consultas públicas online (17\%). São ações tímidas, mas importantes para fomentar uma maior participação dos cidadãos. O desenvolvimento tecnológico representa hoje um momento importante para administração pública, pois serve para mitigar algumas deficiências do setor público, que sempre foi caracterizado por ineficiência, ineficácia, falta de transparência e custos excessivos. O uso das tecnologias de comunicação, como a internet, nas ações governamentais vem se tornando algo essencial para corrigir essas distorções e reformular as administrações públicas, tornando-as mais eficientes e legítimas perante os atores sociais. Tal constatação traz a questão da necessidade de expansão das redes de distribuição de informações, sobretudo diante da relativa ausência de uma política de informação definida para os diferentes órgãos da administração pública.

PROPORÇÃO DE ÓRGÃOS PÚBLICOS FEDERAIS E ESTADUAIS, POR FORMA DE PARTICIPAÇÃO DO CIDADÃO PELA INTERNET NOS ÚLTIMOS 12 MESES

Percentual sobre o total de órgãos públicos federais e estaduais com acesso à Internet (1)

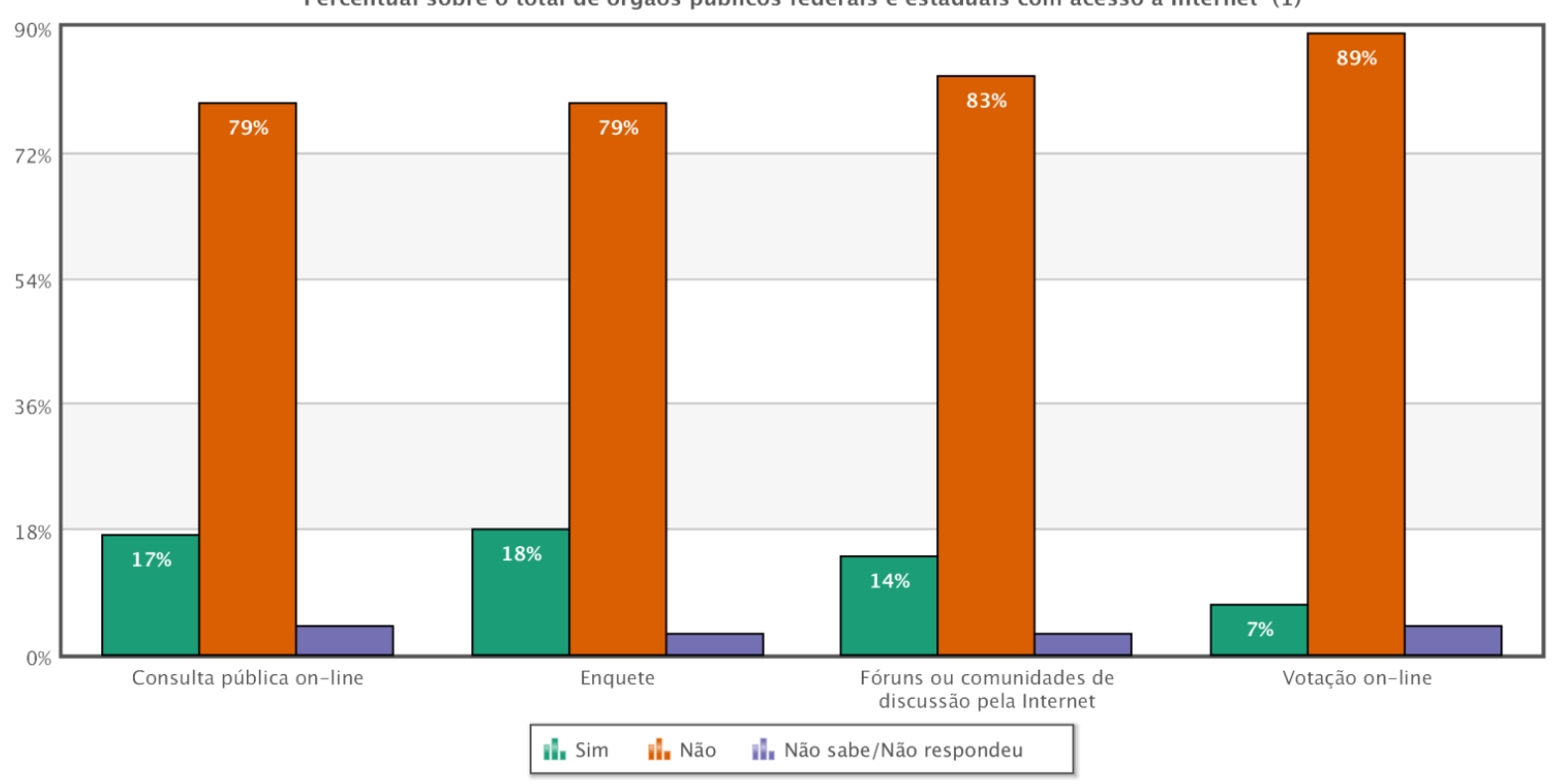

(1) Base: 1.641 órgãos públicos federais e estaduais que declararam ter acesso à Internet nos últimos 12 meses. Respostas múltiplas e estimuladas. Dados coletados entre julho e outubro de 2015.

Fonte: Núcleo de Informação e Coordenação de Ponto BR (NIC.br)

A utilização de sistemas de engenharia imateriais pelo Estado se configura como uma tentativa de aproximação dos cidadãos com a "democracia", no caso uma "democracia 
virtual", ou seja, o Estado usufruindo do ciberespaço de modo a aproximar os cidadãos da gestão do espaço. O virtual está ligado a uma promessa de acontecimento, a uma inovação, uma criação e recriação no espaço que se metamorfoseia incessantemente.

\section{Objetivos e justificativa}

O objetivo geral desse artigo é realizar uma análise espacial do uso e acesso à internet por Unidades da Federação no Brasil a partir do aporte da análise de clusters. O objetivo específico é realizar a partição ideal e identificar os grupos formados para subsidiar políticas públicas específicas para cada grupo apurado. Pretende-se averiguar quais Unidades da Federação estão mais avançadas quanto ao acesso à internet e em quais variáveis, assim como contrário também, quais unidades da Federação encontram-se em pior estágio de acesso e em quais variáveis precisam melhorar.

Esse artigo é pertinente, pois acredita-se que quanto maior o acesso à população a essa tecnologia, maior será sua participação nos processos decisórios do planejamento territorial nas escalas local, regional e nacional. Entender esse processo da ciberdemocracia no planejamento territorial é primordial para garantir a real participação cidadã em processos democráticos.

O planejamento territorial tem por finalidade propiciar um diagnóstico preciso sobre o meio físico-biótico, socioeconômico e sobre sua organização institucional e oferece ainda diretrizes para determinadas ações, as quais deverão refletir os diferentes interesses dos cidadãos. Assim, acredita-se que o uso da Estatística Multivariada possa contribuir para um sistema de planejamento mais eficaz, onde os investimentos e esforços, tanto do governo quanto da iniciativa privada, serão aplicados de acordo com as peculiaridades das unidades de planejamento/conglomerados formados.

Sendo assim, o conhecimento sobre a distribuição espacial do dessa tecnologia é importante para fomentar políticas públicas de acesso à internet para a população do país, pois a partir de um cluster podemos ter uma melhor compreensão dos fatores da dinâmica da sua distribuição. 


\section{Metodologia}

Os dados são provenientes da Pesquisa Nacional por Amostra de Domicílios (PNAD) de 2016 sobre Acesso à Internet e à Televisão e Posse de Telefone Móvel Celular para Uso Pessoal $^{3}$. Este trabalho utiliza apenas dez variáveis referentes ao acesso à Internet associados às UFs do Brasil e o Distrito Federal. De modo complementar ao longo do trabalho serão utilizados os dados do Centro de Estudos sobre Tecnologia da Informação e Comunicação (CETIC) relacionados aos domicílios e a dinâmica do governo eletrônico no Brasil ${ }^{4}$.

O presente artigo emprega o método de investigação análise-síntese. A proposta é utilizar a corrente empírico-analítica para analisar dados secundários tratados com o aporte de uma técnica de Estatística Multivariada, chamada Análise de Cluster. As análises estatísticas foram realizadas no software estatístico MiniTAB versão 17. Para a elaboração do mapa utilizou se o software ArcGIS versão 10.2.

A Estatística Multivariada apresenta muitas técnicas como: análise de componentes principais, análise fatorial, análise de correlações canônicas, análise discriminante e análise de agrupamentos. Esse artigo utiliza a técnica de Análise de Clusters, também conhecida como Análise de Agrupamentos ou Conglomerados (MATOS, 2007).

O objetivo da Análise de Clusters é o de organizar os elementos em grupos (clusters), com base nas informações quanto à proximidade de seus elementos em determinadas variáveis. No processo de formação dos agrupamentos, é importante minimizar a distância intra grupos e maximizar a distância inter grupos. O resultado obtido a partir da aplicação dessa técnica é um conjunto de grupos com coesão interna e isolamento externo, ou seja, elementos dentro de um mesmo grupo são tão similares quanto possível e são, ao mesmo tempo, tão dissimilares quanto possível dos elementos presentes nos demais grupos (MATOS, 2007).

Os grupos devem manter o máximo de similaridade interna e dissimilaridade externa nestas variáveis. É interessante usar a Análise de Clusters quando se pretende observar a hierarquia dos dados, quando os dados forem categorizados e quando se busca estabelecer partição através do grau de similaridade e da distância entre grupos. O objetivo è criar grupos e posteriormente analisar o conjunto de dados dentro de cada grupo investigando as similaridades. A análise de agrupamento é uma técnica útil para trabalhar com dados geográficos, com índices e indicadores do IBGE por exemplo. Os dados analisados são agrupados de acordo com as características comuns observadas entre eles.

As etapas de formação de clusters nos fornecem um desenho dos passos a seguir até 
chegar à interpretação dos resultados. Após coleta dos dados primários ou secundários e a seleção das variáveis de interesse, deve se proceder à seleção do algoritmo de agrupamento e optar em usar um método hierárquico ou não hierárquico. Os métodos são complementares e não competitivos.

O método hierárquico pode ser aglomerativo ou divisivo. Esse método constrói uma hierarquia da partição. Dentro do protocolo do método aglomerativos, cada elemento começa no seu próprio grupo e, posteriormente, novos agrupamentos são formados a partir da similaridade. Assim, os grupos vão se formando por proximidade.

No método divisivo primeiramente as observações começam em um único conglomerado a partir das observações mais distantes e a partir das etapas posteriores formam finalmente um grupo isolado. (FÁVERO, 2009). Ao optar pela técnica de análise de agrupamento, também é necessário usar uma medida de distância. A mais usual e a que esse artigo utilizará é a distância euclidiana, que é obtida de uma distância mais geral (Distância de Minkowski).

$$
\begin{gathered}
d_{a b}=\left[\sum_{j=1}^{p}\left(X_{a j}-X_{b j}\right)^{2}\right]^{1 / 2} \\
p=1,2, \cdots, j ; \\
X_{a j}=\text { valor da vaviável } j \text { para o indivíduo } a ; \\
X_{b j}=\text { valor da variável } j \text { para o indivíduo } b . \\
d_{a b}=\left[\left(X_{a}-X_{b}\right)^{\prime} \cdot\left(X_{a}-X_{b}\right)\right]^{1 / 2} \\
X_{a}=\left[\begin{array}{llll}
X_{a 1} & X_{a 2} & \cdots & X_{a p}
\end{array}\right]^{\prime}=\text { vetor de características do indivíduo } a ; \\
X_{b}=\left[\begin{array}{llll}
X_{b 1} & X_{b 2} & \cdots & X_{b p}
\end{array}\right]^{\prime}=\text { vetor de características do indivíduo } b .
\end{gathered}
$$

Para as variáveis quantitativas ou qualitativas, os métodos de ligação simples, completa e da média são indicados. Alguns métodos são específicos para as variáveis quantitativas, pois possuem como base a comparação de vetores de média. Entre esses métodos pode se citar o centroide e de Ward. (MINGOTI, 2013).

Esse artigo utilizará o método de Ward, pois, de acordo com a literatura ele tende a 
gerar grupos com aproximadamente o mesmo número de componentes. O método tem a tendência a produzir agrupamentos de tamanhos iguais, convexos e compactos, além de realizar um trabalho melhor de redução da heterogeneidade, isto é, da variância da partição (LATTIN et al, 2011).

Para Rogerson (2012) o método de Ward escolhe aquela fusão que resulta no menor aumento na soma de quadrados internos, assim a variabilidade dentro do grupo permanece a menor possível. Reforçando a ideia de acordo com (Hair et al, 200), o método Ward realizar uma combinação baseada na minimização da soma interna de quadrados no conjunto completo de agrupamentos separados ou disjuntos.

Os métodos não hierárquicos necessitam de uma referência sequencial com a seleção de pontos sementes. $\mathrm{O}$ algoritmo mais comum nesse caso é K-means ou K-médias. É um método diferenciado do anterior, pois é necessário realizar a seleção das sementes de agrupamentos. Portanto dependendo da posição escolhida ocorrerão resultados distintos em função de uma alteração na ordem das observações no banco de dados utilizado. (FÁVERO, 2009). A escolha da partição final é um dos grandes gargalos da análise de agrupamentos. Existem alguns métodos para determinar a partição de grupos pertinente. O coeficiente de determinação apresenta uma medida de decisão. Ele representa a proporção da variabilidade total explicada pela partição em grupos dado pela fórmula:

$$
\mathbf{R}^{2}=\frac{S S B}{S S T C}
$$

Onde,

SSB: Variabilidade entre os conglomerados

SSTc: Variabilidade total

O coeficiente de determinação $\mathrm{R}^{2}$ representa a proporção da variabilidade total explicada pela partição em grupos. Outro critério de decisão passível de ser utilizado é o pseudo-F F. Trata-se de uma medida que capta a análise de custo-benefício entre a simplicidade e adequação. Essa medida baseia-se em uma razão da soma média de quadrados entre os grupos pela soma média de quadrados dentro do grupo (LATTIN et al, 2011).

O pseudo-F é definido como: 
Vandeir Robson da Silva Matias

$$
\mathbf{P F}=\left(\frac{\boldsymbol{n}-\boldsymbol{g} *}{\mathrm{~g} *-\mathbf{1}}\right)\left(\frac{\boldsymbol{R}^{2}}{\mathbf{1}-\boldsymbol{R}^{2}}\right)
$$

Onde,

$\mathrm{n}=$ Número de grupos

$\mathrm{g}^{*}=$ Número de clusters da partição

$\mathrm{R}^{2}=$ Variabilidade total explicada pela divisão

Após o cálculo do Pseudo-F- F deve-se buscar o maior valor, pois ele estaria relacionado com a menor probabilidade de significância do teste o que rejeita também a igualdade de vetores de médias populacionais (dos grupos) com maior significância. Assim, o resultado obtido seria a partição com maior heterogeneidade entre grupos (MINGOTI, 2013).

No quesito validação do agrupamento, o resultado final é específico para um conjunto particular de objetos ou indivíduos. Assim, a validação nem sempre é pertinente, não é conveniente usar a solução de agrupamentos para dizer qualquer coisa sobre um elemento que pertencente a um agrupamento de fora da amostra (LATTIN, et al, 2011).

Uma das principais desvantagens dessa técnica análise de clusters é a tentativa de tratar observações de diferentes medidas e a possiblidade de perda de informação. Destaca-se que ainda o aumento indesejado do número de variáveis, a ineficiência quando grande volume de informações precisa ser agrupado, a impossibilidade de se consolidar resultados discordantes e a dificuldade na determinação dos pesos da medida de proximidade conjunta (MATOS, 2007; MINGOTI, 2013).

Fávero (2009) destaca que os outliers podem interferir nos resultados. Trata-se de uma técnica sensível à inclusão de variáveis com comportamento atípico. Portanto o pesquisador deve decidir a manutenção ou não desses outliers no seu banco de dados.

Ressalta-se que vários métodos de análise de cluster focam, principalmente, em dados caracterizados por variáveis contínuas. Entretanto, na presença de dados categóricos, algumas aproximações são utilizadas, como a transformação destas em contínuas, atribuindo valores numéricos às suas categorias, ou em binárias, fazendo com que cada uma das suas categorias se torne uma variável que represente presença ou ausência desse determinado atributo (MATOS, 2007).

\section{O Banco de Dados Utilizado}

A base de dados real utilizada neste trabalho é intitulada Acesso à Internet e à Televisão e Posse de Telefone Móvel Celular para Uso Pessoal, é oriunda da PNAD-2016. As unidades 
de análise são Unidades da federação, vinte seis ao todo mais o Distrito Federal. As variáveis desta base de dados referem-se ao uso, no domicílio, de internet, rádio, televisão, telefone fixo convencional e telefone fixo móvel, e à presença de micro computador, tablet, banda larga fixa e móvel, dentre outras variáveis. O IBGE seleciona essas variáveis a partir da sugestão da agência da ONU especializada em tecnologias de informação e comunicação, União Internacional de Telecomunicações (UIT, em inglês: International Telecommunication Union - ITU).

Esse artigo optou por trabalhar exclusivamente com os dados referentes à internet para cada vinte e seis Unidades da Federação (UF) além do Distrito Federal, ver Tabela 1. Foram selecionadas as seguintes dez variáveis sobre utilização da internet:

Var 1- Pessoas de 10 anos ou mais de idade que utilizaram a Internet, no período de referência dos últimos três meses, por grupos de idade, segundo as Grandes Regiões e as Unidades da Federação - 4o trimestre de 2016.

Var 2- Pessoas de 14 anos ou mais de idade que tinham telefone móvel celular para uso pessoal, por situação de ocupação na semana de referência e acesso à Internet por telefone móvel celular para uso pessoal, segundo as Grandes Regiões e as Unidades da Federação - 4o trimestre de 2016

Var 3- Domicílios particulares permanentes em que havia utilização da Internet, total e por banda larga, segundo as Grandes Regiões e as Unidades da Federação - 4o trimestre 2016

Var 4- Moradores em domicílios particulares permanentes em que havia utilização da Internet, total e por banda larga no domicílio, segundo as Grandes Regiões e as Unidades da Federação - 4o trimestre de 2016

Var 5- Domicílios particulares permanentes, por existência de utilização da Internet, segundo as Grandes Regiões e as Unidades da Federação - 4o trimestre 2016

Var 6- Moradores em domicílios particulares permanentes, por existência de utilização da Internet no domicílio, segundo as Grandes Regiões e as Unidades da Federação - 4o trimestre 2016

Var 7- Domicílios particulares permanentes em que havia utilização da Internet, por utilização de telefone móvel celular para acessar a Internet, segundo as Grandes Regiões e as Unidades da Federação - 4o trimestre de 2016 
Var 8- Moradores em domicílios particulares permanentes em que havia utilização da Internet, por utilização de telefone móvel celular para acessar a Internet no domicílio, segundo as Grandes Regiões e as Unidades da Federação - 4o trimestre de 2016 Var 9-Domicílios particulares permanentes em que havia utilização da Internet, por utilização de televisão para acessar a Internet, segundo as Grandes Regiões e as Unidades da Federação - 4o trimestre de 2016

Var 10- Pessoas de 10 anos ou mais de idade que tinham telefone celular para uso pessoal, por condição de estudante e o acesso à Internet por telefone móvel celular para uso pessoal, segundo as Grandes Regiões e as Unidades da Federação - 4o trimestre de 2016.

Tabela 1-Banco de dados das variáveis selecionadas

\begin{tabular}{|c|c|c|c|c|c|c|c|c|c|c|}
\hline Estado & Var1 & Var2 & Var3 & Var4 & Var5 & Var6 & Var7 & Var8 & Var9 & Var10 \\
\hline Rondônia & 885 & 1065 & 369 & 846 & 594 & 1785 & 369 & 1174 & 369 & 193.2 \\
\hline Acre & 352 & 412 & 137 & 310 & 230 & 808 & 137 & 483 & 137 & 94.4 \\
\hline Amazonas & 1703 & 1909 & 662 & 1985 & 1048 & 3879 & 662 & 2469 & 662 & 403.8 \\
\hline Roraima & 241 & 260 & 95 & 293 & 133 & 460 & 95 & 342 & 95 & 59.4 \\
\hline Pará & 3583 & 4131 & 1411 & 3490 & 2337 & 8269 & 1411 & 5257 & 1411 & 782.6 \\
\hline Amapá & 389 & 453 & 165 & 412 & 207 & 782 & 165 & 643 & 165 & 110.2 \\
\hline Tocantins & 745 & 925 & 303 & 557 & 490 & 1527 & 303 & 1026 & 303 & 176.9 \\
\hline Maranhão & 2467 & 3190 & $\overline{946}$ & 3506 & 1987 & 6935 & $\overline{946}$ & 3506 & 946 & 587.9 \\
\hline Piauí & 1356 & 1816 & 532 & 1860 & 1009 & 3216 & 532 & 1860 & 532 & 366.7 \\
\hline Ceará & 3915 & 5061 & 1582 & 5397 & 2851 & 8986 & 1582 & $\begin{array}{|lll|}5 & 397 \\
\end{array}$ & 1582 & 940.5 \\
\hline $\begin{array}{l}\text { Rio Grande } \\
\text { do Norte }\end{array}$ & 1827 & 2220 & 720 & 2453 & 1108 & 3488 & 720 & 2453 & 720 & 428.8 \\
\hline Paraíba & 1862 & 359 & 776 & 2621 & 1278 & 3986 & 776 & 2621 & 776 & 467.7 \\
\hline$\overline{\text { Pernamb }}$ & 4343 & 5644 & 1766 & 5789 & 3098 & 9376 & 1766 & 5789 & 1766 & 924.8 \\
\hline Alagoas & 1417 & 1878 & 592 & 1988 & 1070 & 3359 & 592 & 1988 & 592 & 337.5 \\
\hline Sergipe & 1138 & 1373 & 493 & 1598 & 760 & 2274 & 493 & 1598 & 493 & 247.8 \\
\hline Bahia & 7274 & 8903 & 2971 & 9489 & 5182 & 15282 & 2971 & 9489 & 2971 & 1630.4 \\
\hline Minas Gerais & 11897 & 14177 & 3753 & 15945 & 7243 & 21034 & 5052 & 15945 & 5052 & 2538.2 \\
\hline Espírito & 2357 & 2734 & 758 & 3066 & 1380 & 3985 & 982 & 3066 & 982 & 464.8 \\
\hline Rio de J & 10982 & 11753 & 3483 & 13845 & 6027 & 16673 & 4628 & 13845 & 4628 & 1948.8 \\
\hline São Paulo & 30007 & 31625 & 9787 & 38284 & 15421 & 44891 & 12401 & 38284 & 12401 & 5440.2 \\
\hline Paraná & 6654 & 7644 & 2740 & 8434 & 3932 & 11263 & 2740 & 8434 & 2740 & 1404.6 \\
\hline Santa Catarina & 4237 & 4716 & 1783 & 5443 & 2435 & 6932 & 1783 & 5443 & 1783 & 847.0 \\
\hline $\begin{array}{l}\text { Rio Grande } \\
\text { do Sul }\end{array}$ & 6761 & 8205 & 2992 & 8778 & 4178 & 11288 & 2992 & 8778 & 2992 & 1402.8 \\
\hline $\begin{array}{l}\text { Mato Grosso } \\
\text { do Sul }\end{array}$ & 1612 & 1841 & 667 & 2094 & 901 & 2628 & 667 & 2094 & 667 & 328.0 \\
\hline Mato Grosso & 1815 & 2192 & 753 & 2403 & 1114 & 3270 & 753 & 2403 & 753 & 424.4 \\
\hline Goiás & 4035 & 4704 & 1646 & 5243 & 2291 & 6727 & 1646 & 5243 & 1646 & 850.6 \\
\hline Distrito Federal & 2218 & 2238 & 907 & 2773 & 1014 & 2997 & 907 & 2773 & 907 & 469.8 \\
\hline
\end{tabular}


Fonte: PNAD: Acesso à Internet e à Televisão e Posse de Telefone Móvel Celular para Uso Pessoal, $4^{\circ}$ trimestre de 2016.

\section{Resultados e Discussão}

Inicia-se a análise apresentando a Tabela 2 com as estatísticas descritivas das variáveis selecionadas.

Tabela 2- Estatísticas descritivas das variáveis selecionadas

\begin{tabular}{|r|r|r|c|r|r|r|r|r|r|}
\hline \hline Variável & Média & D.P. & C.V. & Mínimo & Q1 & Mediana & Q3 & Máximo & Curtose \\
\hline Var. 1 & 4299 & 5970 & 138,87 & 241 & 1356 & 2218 & 4343 & 3007 & 13,55 \\
\hline Var. 2 & 4942 & 6385 & 129,20 & 260 & 1816 & 2359 & 5644 & 31625 & 11,76 \\
\hline Var. 3 & 1585 & 1951 & 123,14 & 95 & 532 & 776 & 1783 & 9787 & 11,98 \\
\hline Var. 4 & 5515 & 7667 & 139,02 & 293 & 1860 & 776 & 5489 & 38284 & 13,10 \\
\hline Var. 5 & 2567 & 3157 & 122,96 & 133 & 901 & 2773 & 3098 & 15421 & 10,36 \\
\hline Var. 6 & 7633 & 9089 & 119,08 & 460 & 2628 & 1278 & 9376 & 44891 & 10,70 \\
\hline Var. 7 & 1780 & 2483 & 139,49 & 95 & 532 & 3985 & 1783 & 12401 & 13,13 \\
\hline Var. 8 & 5645 & 7617 & 134,95 & 342 & 1860 & 907 & 5489 & 38284 & 13,25 \\
\hline Var. 9 & 1780 & 2483 & 139,49 & 95 & 532 & 2773 & 1783 & 12401 & 13,13 \\
\hline Var. 10 & 884 & 1095 & 123,82 & 59 & 328 & 468 & 940 & 5440 & 11,55 \\
\hline \hline
\end{tabular}

DP:desvio-padrão; C.V.: coeficiente de variação; Q1: primeiro quartil; Q3: terceiro quartil.

É necessário chamar a atenção que as unidades de medida das variáveis são diferentes, o que reflete nos valores observados. A variável 1 (Pessoas de 10 anos ou mais de idade que utilizaram a Internet, no período de referência dos últimos três meses, por grupos de idade, segundo as Grandes Regiões e as Unidades da Federação - 4o trimestre de 2016.) apresenta média de 4,299.

Os desvios-padrão são elevados e a outra medida de dispersão, coeficiente de variação é bastante elevado também. O menor coeficiente encontra-se na variável 6 (Moradores em domicílios particulares permanentes, por existência de utilização da Internet no domicílio, segundo as Grandes Regiões e as Unidades da Federação - 4o trimestre 2016 ) 119,08. No geral, na maioria das variáveis selecionadas o coeficiente é alto, representando uma heterogeneidade dos dados. Na Figura 3 são apresentados os histogramas das variáveis.

A Figura 4 mostra os boxplots das variáveis. Todas as variáveis apresentam um outliers que é o estado de São Paulo. Grande parte das variáveis apresentam valores discrepantes. Esse 
Análise do Acesso à Internet nas Unidades da Federação do Brasil: elementos para o planejamento territorial

Vandeir Robson da Silva Matias

aspecto é bastante comum quando a unidade de análise trata-se das Unidades da Federação do país. 
Figura 3- Histograma das dez variáveis selecionadas.

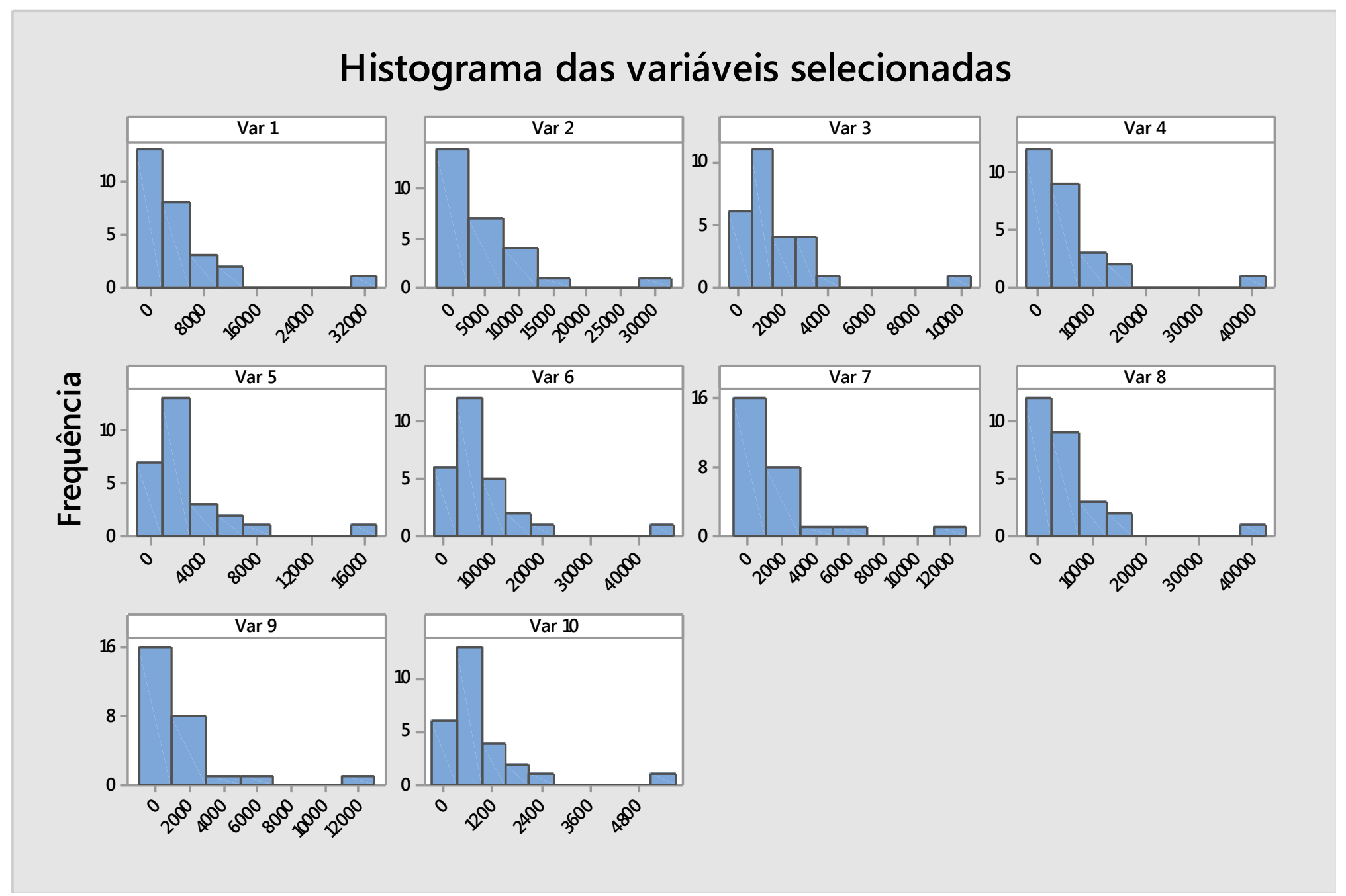


Figura 4- Boxplots das dez variáveis selecionadas.

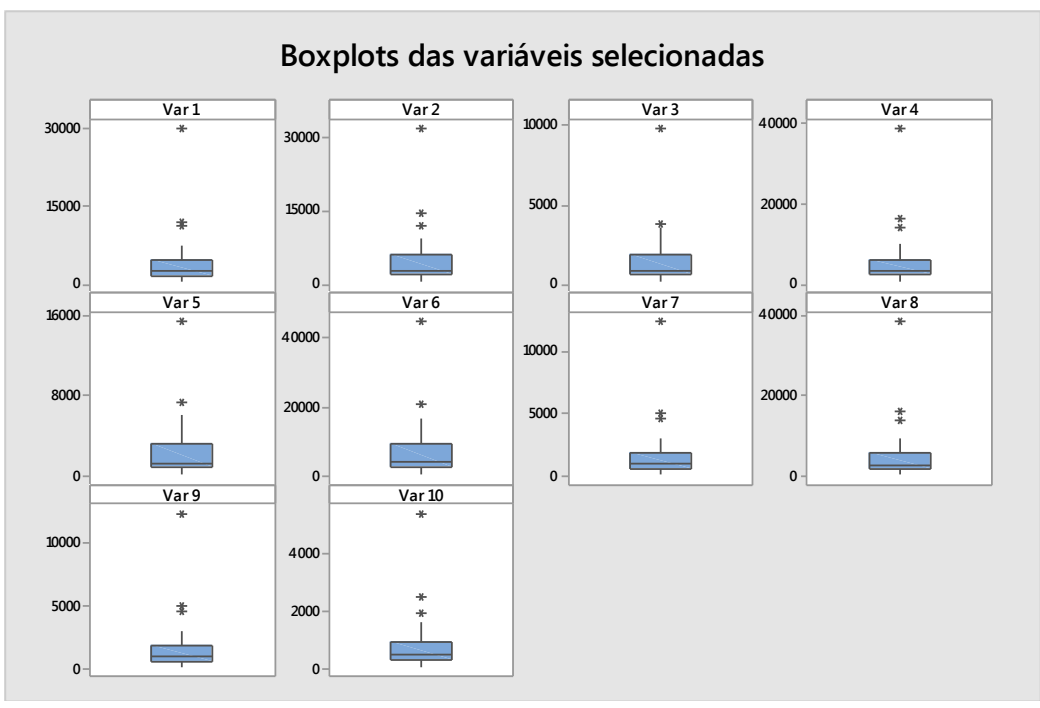

A Figura 5 apresenta o percentual do tipo de equipamento utilizado pelos domicílios para realizar o acesso à internet, segundo as regiões do país.

Figura 5- Domicílios com acesso a internet por tipo de equipamento

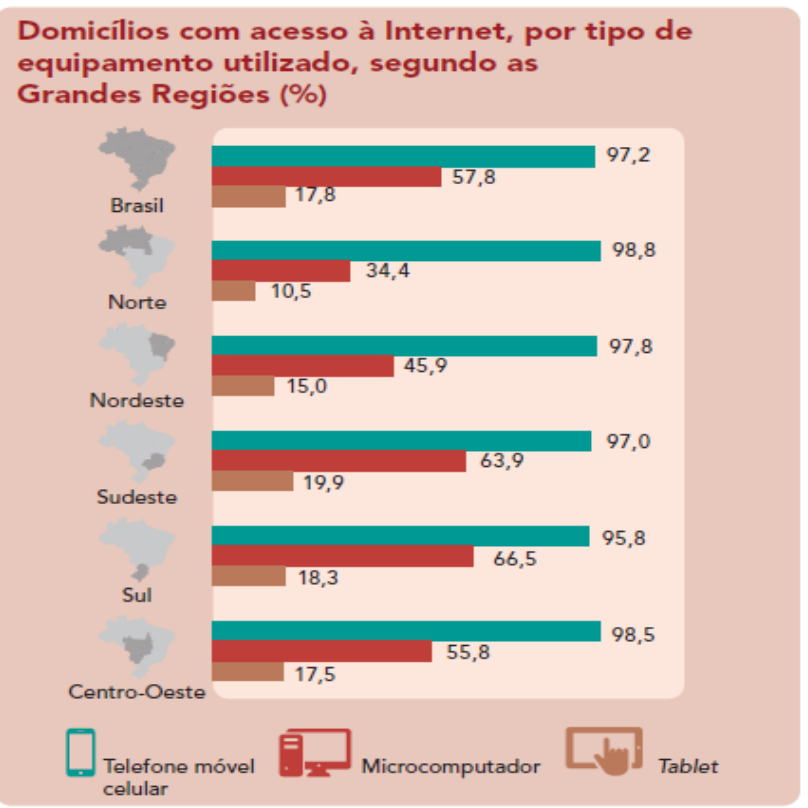

Fonte: IBGE, Diretoria de Pesquisas, Coordenação de Trabalho e Rendimento, Pesquisa Nacional por Amostra de Domicílios Contínua 2016.

A utilização do microcomputador recebe destaque nas Regiões Sudeste e Sul, $63,9 \%$ e $66,5 \%$ respectivamente. Nas demais regiões predomina o acesso via telefone móvel celular, com mais de $90 \%$ em todas as regiões mostrando a popularização desse tipo de equipamento no Brasil. 
Quanto ao acesso de acordo com o sexo, apresenta-se a Figura 6 em sequência. Dentro da amostra selecionada, as mulheres são as que mais acessam, ocupadas ou não. No geral a porcentagem em $(65,3 \%)$ e Homens $(63,7 \%)$.

Figura 6- Percentual de pessoas que utilizaram a internet, no período de referência dos últimos três meses, na população de 10 anos ou mais de idade, por sexo, segundo as Grandes Regiões- 2014.

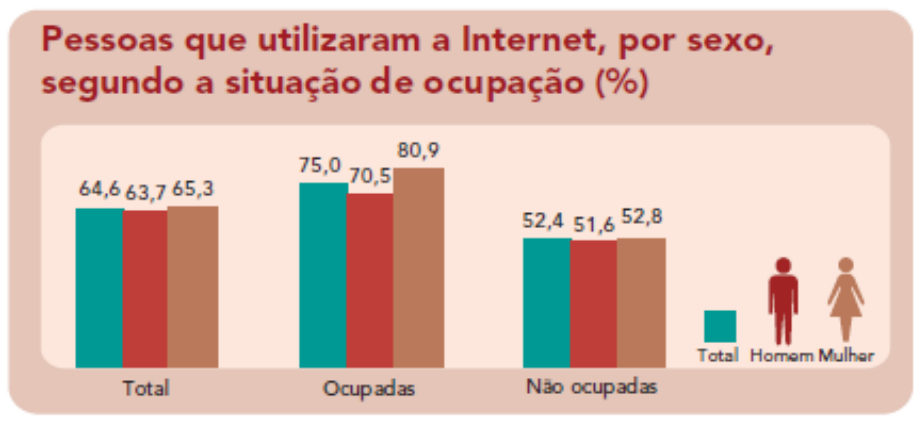

Fonte: IBGE, Diretoria de Pesquisas, Coordenação de Trabalho e Rendimento,Pesquisa Nacional por Amostra de Domicílios Contínua 2016.

Nesse contexto, é possível dizer que o uso das TDICs, faz-se presente no cotidiano da população, mas também estão associadas a algumas características como à renda, e outras diferenças adquiridas pelos indivíduos (escolaridade e experiência), diferenças de remuneração no emprego, a faixa etária, ao tipo de ocupação dentre outros fatores.

Para (Dulci et al, 2007) as desigualdades de rendimentos são relevantes para a definição das desigualdades sociais, já que a posição diferenciada das pessoas na estrutura ocupacional está relacionada aos diferenciais de rendimentos do trabalho. A Instrução e a renda também estão relacionados. Historicamente verifica se que os trabalhadores com baixos rendimentos possuem menos capital sociocultural e participam menos da dinâmica das TDICs. Possuem menos acesso a elas e realizam menos atividades relacionadas ao seu aporte.

\section{Análise de Clusters}

A ampliação do acesso as TDIC, o diagnostico e a analise a dinâmica da internet por UFs auxilia no entendimento dos pontos fracos dessa dinâmica, percebendo quais 
são os desafios e onde é necessário avançar para melhorar o acesso da população. A Análise de Clusters é uma técnica que ajuda nesse processo.

A partir do referencial teórico, analisado optou-se: pelo método hierárquico, por não conhecer a partição (número de grupos) ideal; pela distância euclidiana, por ser a mais utilizada; e pelo método de ligação de Ward, por garantir maior homogeneidade entre os grupos formados. Os resultados da análise realizada são mostrados na tabela $3 \mathrm{e}$ figura 7 (Dendograma).

Tabela 3- Resultados da análise de clusters

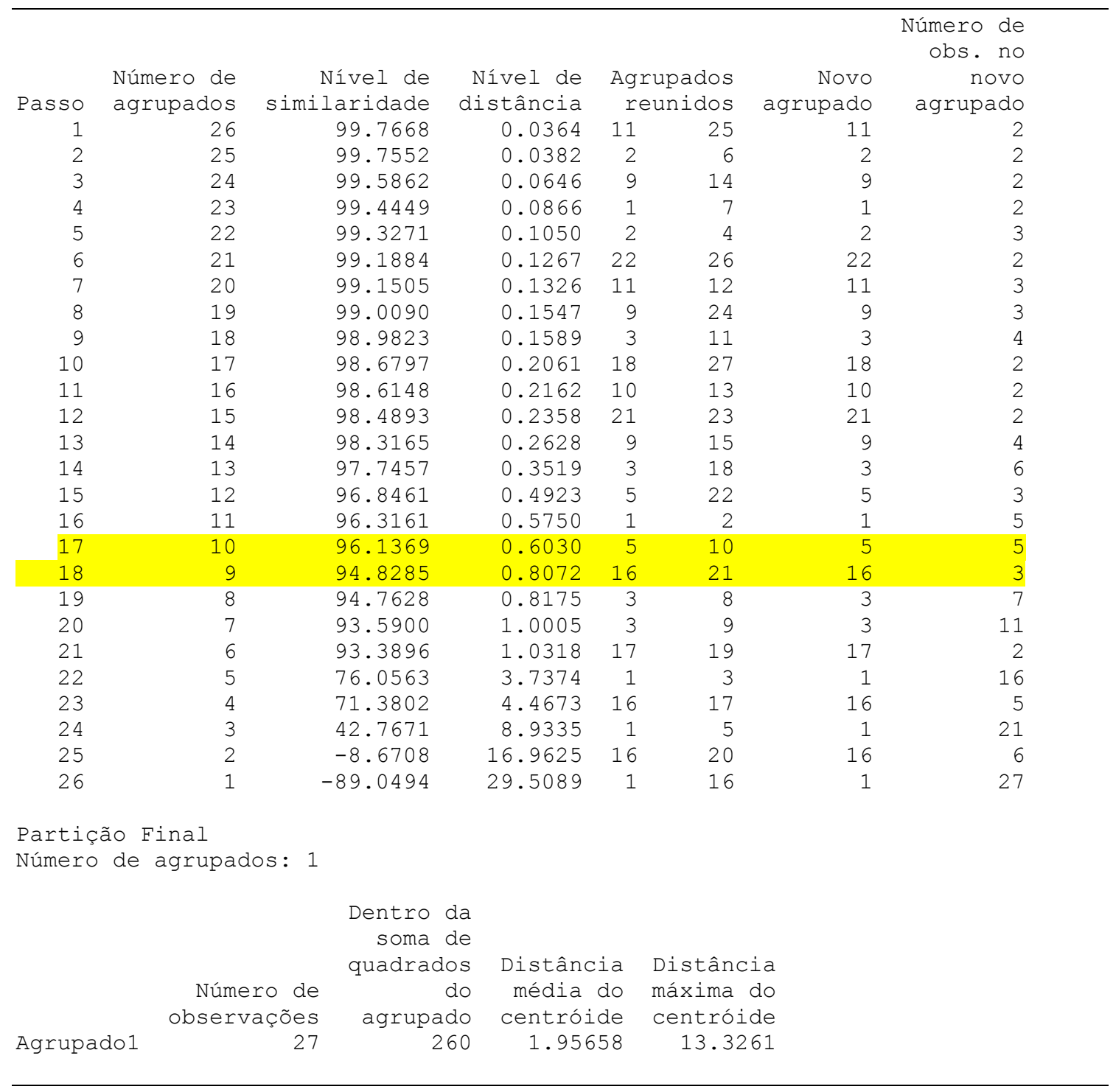


Figura 7- Dendograma: agrupamento das UF's.

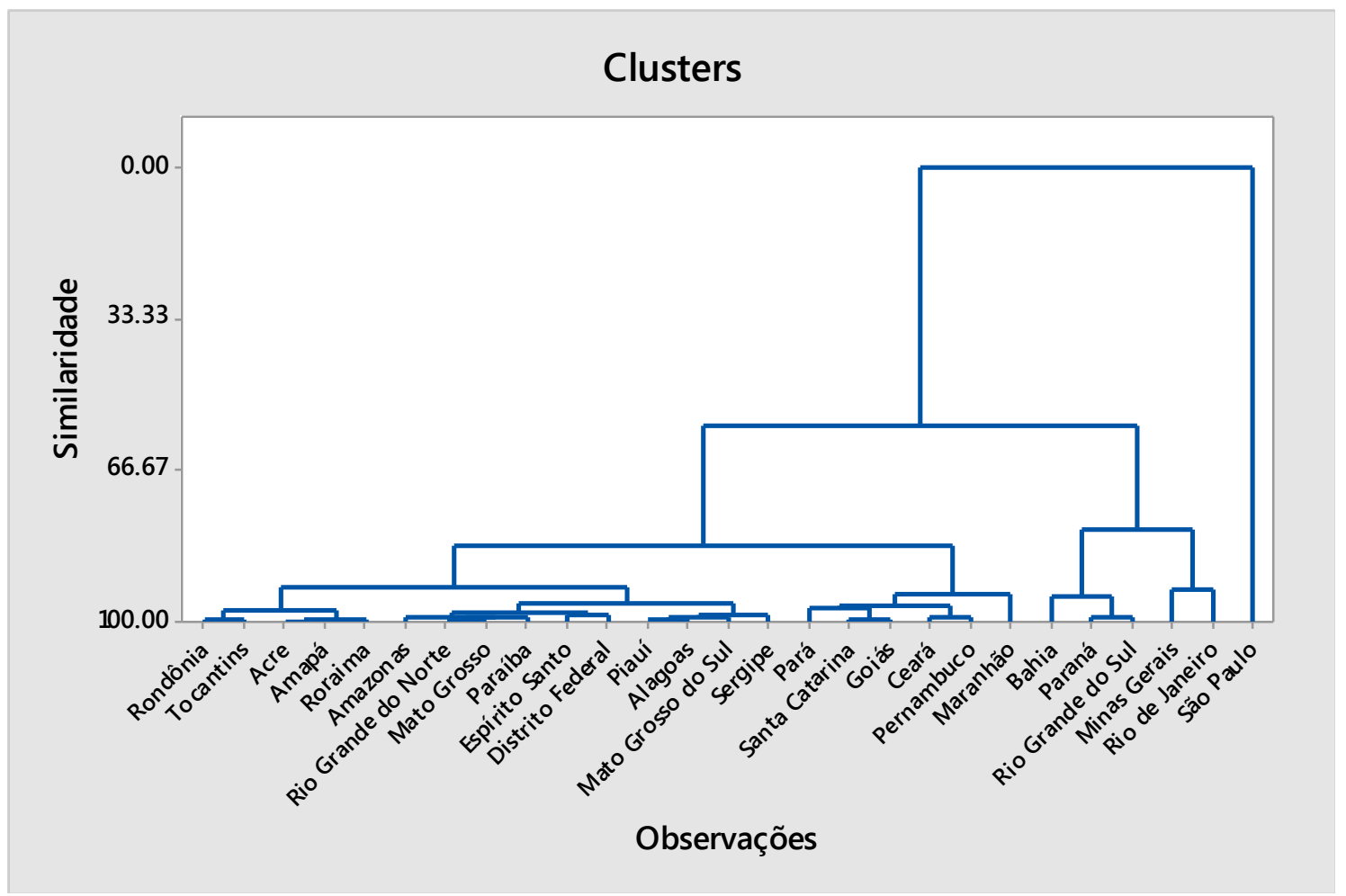

A análise do Dendograma aponta para a formação de aproximadamente seis a nove grupos, que serão confirmados por medidas do $\mathrm{R}^{2}$ e o pseudo-F. A área delimitada de amarelo na tabela 3 corresponde aos agrupamentos que serão testados para os cálculos do $\mathrm{R}^{2}$ e Pseudo-F F com o auxílio da soma do quadrado total expresso em sequência, porque corresponde ao salto de similaridade observado. A análise do nível de similaridade nos permite concluir que o intervalo que varia entre 9 a 10 grupos é um marco na queda dos valores apresentados.

A Tabela 6 em sequência apresenta os resultados do $R^{2}$ e pseudo-F F para as partições selecionadas para a análise: 9 e 10.

A análise do nível de similaridade nos permite concluir que a partição 9 apresenta o maior $\mathrm{R}^{2}(99,67 \%)$, valor também próximo da partição $10(99,78 \%)$. O pseudo $\mathrm{F}$ da partição 9 é de 110,81 e da partição 10 é 93,02. A partir da análise realizada optou-se pelo $\mathrm{K}=9$. 


\section{Vandeir Robson da Silva Matias}

Tabela 3- Medidas para a tomada de decisão

\begin{tabular}{|c|c|c|c|c|}
\hline $\begin{array}{c}\text { Número de } \\
\text { clusters }\end{array}$ & $\begin{array}{c}\text { Soma dos } \\
\text { Quadrados } \\
\text { Total }\end{array}$ & $\begin{array}{c}\text { Soma dos } \\
\text { Quadrados } \\
\text { entre clusters }\end{array}$ & $\mathbf{R}^{\mathbf{2}}$ & Pseudo F \\
\hline 10 & 260 & 0,555 & 0,9978 & 93,02 \\
\hline 9 & 260 & 0.842 & 0.9967 & 110,81 \\
\hline
\end{tabular}

A Figura 8 apresenta o Dendograma com a partição em 9 clusters e a Figura 9 o mapa elaborado a partir do número de clusters sugeridos.

Figura 8- Dendograma da partição final com nove clusters.

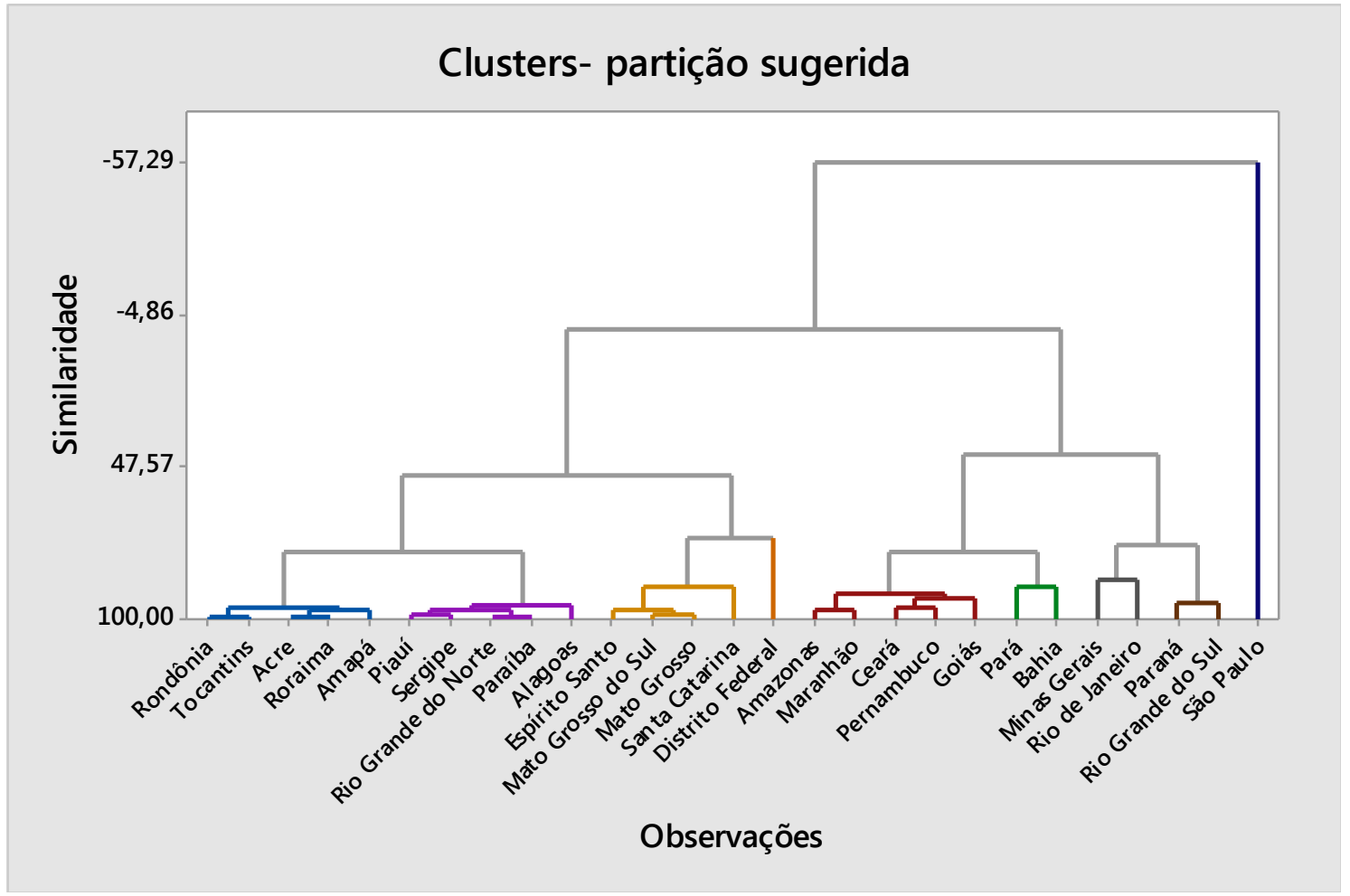

A Tabela 7 apresenta as descritivas dos clusters. A partir dos resultados gerados, é possível traçar os seguintes perfis para os grupos:

Figura 9- Clusters: Acessa a internet no Brasil 


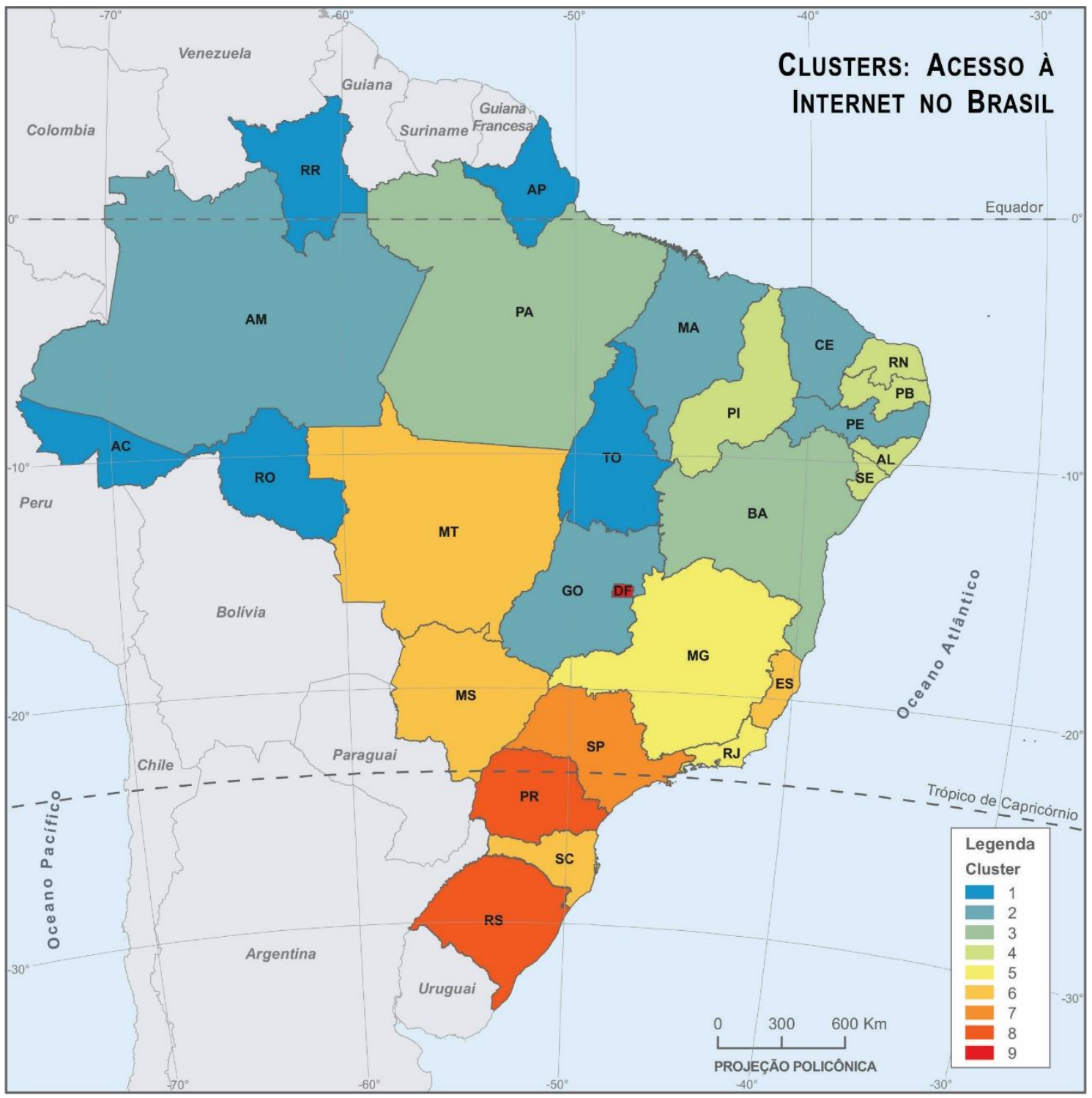

Cluster 1: Acre, Rondônia, Roraima, Amapá e Tocantins.

O primeiro agrupamento é formado em sua maioria por um dos menores quantitativos de pessoas que utilizaram a internet no período de referência e os domicílios utilizam pouco acesso à banda larga para acessar a internet. Grande parte do acesso ocorre com o auxílio de telefone celular ou tablet. Para é esse grupo, é necessário elevar o número de pessoas com acesso à internet, melhor o acesso à banda larga, pois significa uma melhora na condição de conexão. 
Tabela 4- Descritivas dos Clusters

\begin{tabular}{|c|c|c|c|c|c|c|c|c|c|c|c|c|}
\hline Grupos & Estados & Descritivas & Var.1 & Var.2 & Var.3 & Var.4 & Var.5 & Var.6 & Var.7 & Var.8 & Var.9 & Var.10 \\
\hline \multirow[b]{3}{*}{1} & \multirow{3}{*}{$\begin{array}{l}\text { Acre, Rondônia, Roraima, } \\
\text { Amapá e Tocantins }\end{array}$} & \multirow{3}{*}{$\begin{array}{c}\text { Média } \\
\text { Desvio Padrão } \\
\text { Coeficiente de variação }\end{array}$} & 522 & 623 & 213,7 & 484 & 330,6 & 1072 & 213,7 & 733 & 213,7 & 126,8 \\
\hline & & & 277 & 350 & 116,8 & 228 & 199,3 & 557 & 116,8 & 355 & 116,8 & 56,5 \\
\hline & & & 53,02 & 56,25 & 54,66 & 4720 & 6029 & 51,97 & 54,66 & 48,40 & 54,66 & 44,58 \\
\hline \multirow{3}{*}{2} & \multirow{3}{*}{$\begin{array}{c}\text { Amazonas, Maranhão, } \\
\text { Ceará, Goiás e Pernambuco }\end{array}$} & \multirow{3}{*}{$\begin{array}{c}\text { Média } \\
\text { Desvio Padrão } \\
\text { Coeficiente de variação }\end{array}$} & 2875 & 3533 & 1148 & 3795 & 1909 & 6081 & 1148 & 3892 & 1148 & 639 \\
\hline & & & 1239 & 1605 & 522 & 1676 & 859 & 2428 & 522 & 1555 & 522 & 239 \\
\hline & & & 43,10 & 45,44 & 45,48 & 44,15 & 45,03 & 39,93 & 45,48 & 39,94 & 45,48 & 37,4 \\
\hline \multirow[b]{3}{*}{3} & \multirow{3}{*}{$\begin{array}{c}\text { Pará } \\
\text { Bahia }\end{array}$} & \multirow{3}{*}{$\begin{array}{c}\text { Média } \\
\text { Desvio Padrão } \\
\text { Coeficiente de variação }\end{array}$} & 5429 & 6517 & 2191 & 6489 & 3759 & 11775 & 2191 & 7373 & 2191 & 1206 \\
\hline & & & 2610 & 3374 & 1103 & 4242 & 2012 & 4959 & 1103 & 2992 & 1103 & 594 \\
\hline & & & 48,07 & 51,78 & 50,35 & 65,37 & 53,51 & 42,11 & 50,35 & 40,59 & 50,35 & 49,69 \\
\hline \multirow[b]{3}{*}{4} & \multirow{3}{*}{$\begin{array}{c}\text { Piauí, Rio Grande do Norte, } \\
\text { Paraíba, Alagoas e } \\
\text { Sergipe }\end{array}$} & \multirow{3}{*}{$\begin{array}{c}\text { Média } \\
\text { Desvio Padrão } \\
\text { Coeficiente de variação }\end{array}$} & 1520 & 1929 & 622,5 & 2104 & 1045,1 & 3264 & 622,5 & 2104 & 622,5 & 369,7 \\
\hline & & & 314 & 385 & 121,5 & 424 & 187,7 & 625 & 121,5 & 424 & 121,5 & 85,1 \\
\hline & & & 20,67 & 19,07 & 19,52 & 20,14 & 17,97 & 19,14 & 19,52 & 20,14 & 19,52 & 23,03 \\
\hline \multirow[b]{3}{*}{5} & \multirow{3}{*}{$\begin{array}{l}\text { Minas Gerais } \\
\text { Rio de Janeiro }\end{array}$} & \multirow{3}{*}{$\begin{array}{c}\text { Média } \\
\text { Desvio Padrão } \\
\text { Coeficiente de variação }\end{array}$} & 11439 & 12965 & 3618 & 14895 & 6635 & 18854 & 4840 & 14895 & 18,40 & 2243 \\
\hline & & & 647 & 1714 & 191 & 1485 & 859 & 3084 & 300 & 1485 & 300 & 4,17 \\
\hline & & & 5,66 & 13,22 & 5,28 & 9,97 & 12,91 & 16,36 & 6,20 & 9,97 & 6,22 & 18,58 \\
\hline \multirow[b]{3}{*}{6} & \multirow{3}{*}{$\begin{array}{c}\text { Espírito Santo, Santa Catarina } \\
\text { Mato Grosso e } \\
\text { Mato Grosso do Sul }\end{array}$} & \multirow{3}{*}{$\begin{array}{c}\text { Média } \\
\text { Desvio Padrão } \\
\text { Coeficiente de variação }\end{array}$} & 2505 & 2871 & 990 & 3251 & 1458 & 4204 & 1046 & 3251 & 1046 & 516 \\
\hline & & & 1197 & 1284 & 530 & 1516 & 681 & 1901 & 509 & 1516 & 509 & 228 \\
\hline & & & 47,77 & 44,72 & 53,52 & 46,63 & 46,69 & 45,23 & 48,61 & 46,63 & 48,61 & 44,17 \\
\hline \multirow{3}{*}{7} & \multirow{3}{*}{ São Paulo } & \multirow{3}{*}{$\begin{array}{c}\text { Média } \\
\text { Desvio Padrão } \\
\text { Coeficiente de variação }\end{array}$} & 30007 & 31625 & 9757 & 38284 & 15421 & 44891 & 12401 & 38284 & 12401 & 5440,02 \\
\hline & & & $*$ & $*$ & $*$ & $*$ & $*$ & $*$ & $*$ & $*$ & $*$ & $*$ \\
\hline & & & $*$ & $*$ & $*$ & $*$ & $*$ & $*$ & $*$ & $*$ & $*$ & $*$ \\
\hline \multirow{3}{*}{8} & \multirow{3}{*}{$\begin{array}{l}\text { Rio Grande do Sul } \\
\text { Paraná }\end{array}$} & \multirow{3}{*}{$\begin{array}{c}\text { Média } \\
\text { Desvio Padrão } \\
\text { Coeficiente de variação }\end{array}$} & 6707,7 & 7925 & 2866 & 8606 & 4055 & 11276 & 2866 & 8606 & 2866 & 1403,7 \\
\hline & & & 75,8 & 397 & 179 & 243 & 174 & 17,7 & 179 & 243 & 179 & 1,27 \\
\hline & & & 1,13 & 5,01 & 6,33 & 2,82 & 4,29 & 0,16 & 6,23 & 2,82 & 6,23 & 0,09 \\
\hline \multirow{3}{*}{9} & \multirow{3}{*}{ Distrito Federal } & \multirow{3}{*}{$\begin{array}{c}\text { Média } \\
\text { Desvio Padrão } \\
\text { Coeficiente de variação }\end{array}$} & 2218 & 2238 & 907 & 2773 & 1014 & 2997 & 907 & 2773 & 907 & 469,8 \\
\hline & & & $*$ & $*$ & $*$ & $*$ & $*$ & $*$ & $*$ & $*$ & $*$ & $*$ \\
\hline & & & $*$ & $*$ & $*$ & $*$ & $*$ & $*$ & $*$ & $*$ & $*$ & $*$ \\
\hline
\end{tabular}


Cluster 2: Amazonas, Maranhão, Ceará, Pernambuco e Goiás.

Esse grupo apresenta posições inferiores a média relativa ao quantitativo de pessoas e domicílios com acesso a internet. $\mathrm{O}$ acesso à internet ocorre, sobretudo, por telefone móvel celular. Deve se elevar o acesso por microcomputador. O baixo uso do microcomputador aqui está relacionado ao custo do equipamento (MATIAS, 2011).

Cluster 3: Pará e Bahia.

Os estados apresentam pessoas que utilizaram a internet acima da média, assim como o número de domicílios particulares permanentes de utilização da internet por banda larga. Ampliar o rendimento médio mensal per capta é uma das saídas para ampliar o acesso. Para esses estados o acesso também ocorre com o uso do telefone celular na sua maioria.

Cluster 4: Piauí, Rio Grande do Norte, Paraíba, Alagoas e Sergipe.

Esse agrupamento apresenta valores inferiores a médias para todas as variáveis. Observa-se um baixo acesso a internet pelas pessoas e pelos domicílios. O rendimento médio mensal domiciliar nesse grupo precisa ser melhorado para que ocorra uma universalização do acesso à internet que facilitaria, por exemplo, uma maior participação política no planejamento territorial. O nível de instrução da população deve ser melhorado, pois o acesso à internet apresenta relação com essa variável.

Cluster 5: Minas Gerais e Rio de Janeiro

Apresenta bons indicadores como acesso da população à internet e número considerável de domicílios nesse acesso. Todas as variáveis estão acima da média e apresentam baixo coeficiente de variação. A população desses estados acesso mais a internet via microcomputador do que nos grupos analisados anteriormente. Para esse grupo é necessário novos estudos para averiguar as diferenças regionais internas. 
Cluster 6: Espírito Santo, Santa Catarina, Mato Grosso e Mato Grosso do Sul

Trata-se de um cluster que agrega estados de diferentes regiões que precisam de um incremento em relação as todas as variáveis. O número de pessoas com acesso a internet não se aproxima da média. Verifica-se também que $\mathrm{O}$ acesso à banda larga não é eficiente nesse agrupamento. Conexões lentas desestimulam o uso da rede de computadores, também há falta de acesso a níveis mais elevados de instrução nessa região. (MATIAS, 2011).

\section{Cluster 7: São Paulo}

É um cluster que agrega apenas um estado por possuir, algumas particularidades em relação ao seu desenvolvimento socioeconômico. Possui o maior acesso a internet tanto de moradores quanto de domicílios. O aceso ocorre, sobretudo por via de microcomputador. Apresenta a maior taxa de pessoas com ensino médio completo que acessam a internet. Esse destaque deixa São Paulo isolado em grupo, contudo, melhorias devem ser pensadas em relação à disseminação de uma internet mais rápida e eficiente.

Cluster 8: Rio Grande do Sul e Paraná.

Possui um dos melhores rendimentos médios mensais domiciliares per capta e um valor acima da média quanto ao número de pessoas que utilizaram a internet. Temos aqui um caso parecido com o cluster 6, ou seja, indica-se novos estudos para averiguar as diferenças regionais internas quanto ao uso da internet.

\section{Cluster 9: Distrito Federal}

Apesar dos bons indicadores do Distrito Federal é necessário melhorar o acesso à internet nos domicílios, sobretudo nas chamadas cidades satélites. Existe um número considerável de pessoas que acessa a internet via celular e tablet. É necessário melhor o 
grau de instrução da população, o número de pessoas que utilizaram a internet com ensino médio completo foi baixo.

\section{Considerações Finais}

Nesse artigo, defende- se o maior acesso à internet de qualidade para promover a participação da população no processo de planejamento territorial. Contudo, sabemos que apenas o acesso à tecnologia não vai garantir esse feito. A qualidade da do uso da internet nos processos decisórios só será possível mediante regularidade e quando ela puder influenciar de fato as decisões das políticas públicas. Assim, são necessários mecanismos que possibilitem o engajamento cívico no espaço, para produzir debates, ampliando a cultura política da população.

Espera-se que esse artigo explicite algumas evidências nos agrupamentos e que políticas específicas para cada cluster possam ser elaboradas. As políticas públicas do Estado, direta ou indiretamente, afetam profundamente quase todos os aspectos da organização espacial, pois ele é o agente central para o funcionamento da sociedade capitalista, e por isso, também cabe a ele diminuir a pobreza estrutural encontrada no país.

Reforça-se, aqui, que a internet por si só não geram participação no planejamento, mas oferecem elementos pertinentes para tal, uma vez que podem privilegiar elementos caros à democracia, sobretudo aqueles que dizem respeito à participação Assim, a internet pode permitir a comunicação de muitos, e através deles os cidadãos podem mobilizar, participar mais atividade da gestão da cidade, dos governos a partir de um prisma mais tecnológico. (SANTOS, 2008).

Ressalta-se que a internet não cria nada de novo que não existe na realidade. Ela altera de inúmeras maneiras, as experiências de interação humana na sociedade. Existem várias organizações sociais, novas unificações coletivas novas formas de lutas políticas e novas formas de se fazer política gerando tempos e espaços diferentes, pois a internet aqui é traduzida como um canal de participação, expressão e busca de informações pelos cidadãos, permitindo aos indivíduos ou à coletividade acompanhar políticas públicas e participar da tomada de decisão.

Planejar é necessário, pois, a sociedade produz seus meios de vida a partir de um intercâmbio. Esse artigo buscou analisar, através da Estatística Multivariada o acesso à 
internet no Brasil. Constata-se a importância da Internet para participação civil, levando em conta participação, planejamento e gestão. A Internet propicia o advento de serviços cívicos, centros de informação, sistemas de informação, pesquisas junto aos cidadãos, etc. Existem mecanismos que podem potencializa a participação como os e-mails, listas de discussão, formas de votos, sondagens, sugestões orçamentárias, transferências, sistemas de apoio a decisões complexas.

Vislumbra-se uma interatividade entre as TDICs e o exercício da cidadania em modelos de cidades digitais no contexto da chamada sociedade da informação. Nessa perspectiva, informação e comunicação são considerados fatores chaves para 0 exercício da cidadania e ampliação da participação dos cidadãos em processos decisórios.

A análise de cluster foi essencial para a criação de grupos e definição dos perfis. A separação das Unidades da Federação em conglomerados foi viável para conseguir agrupar estados similares entre si e divergentes em relação aos outros grupos. Assim, é possível ter maior assertividade na formulação de políticas públicas de inclusão digital já que se tratando de planejamento territorial os recursos são escassos.

Assim, a contribuição desse artigo encontra-se na esfera da possibilidade de redefinição de políticas públicas para que mais pessoas possuem ter acesso à internet e a participação população nas decisões eletrônicas. O essencial é contribuir para o reconhecimento do papel desempenhado pela tecnologia no processo de planejamento.

São pertinentes e urgentes pesquisas de cunho informacional que avancem na reflexão dessa sociedade contemporânea com redes invisíveis, espaços tradicionais e virtuais, buscando uma nova abordagem do território que deve estar ligado às teorias tradicionais e as do mundo técnico-científico-informacional. Além de auxiliar no debate do aproveitamento das políticas públicas de inclusão enquanto elementos de valorização dos lugares, organização recursos e projetos que favorecem a trocas de saberes e de experiências criando redes de ajuda mútua, desenvolvendo maior participação da população nas decisões políticas.

Espera-se contribuir para novas maneiras de pensar a política, a participação e o planejamento territorial favorecendo a reconstituição de laços sociais, desburocratização das administrações, otimização do tempo real, racionalização dos recursos e equipamentos coletivos das cidades, experimentar novas formas democráticas. Os 
indivíduos estarão mais propensos a participar do planejamento da sua cidade, do seu estado ou do seu país se possuir acesso à internet e estiverem de posse de motivos e oportunidades necessários para fazê-lo.

\section{Notas}

\footnotetext{
${ }^{1}$ Entendido como princípio de gestão essencial ao desenvolvimento da democracia eletrônica, o accountability configura-se como uma das formas de responsabilidade democrática da administração pública. Com o objetivo de promover a transparência dos atos públicos e colaborar para a cultura da prestação de contas na política contemporânea, o accountability, é uma das formas mais valiosas de estreitar o laço entre cidadão e as organizações públicas (MATIAS, 2011, p.151).

${ }^{2}$ O governo eletrônico é a contínua otimização da prestação de serviços do governo, da participação dos cidadãos e da administração pública pela transformação das relações internas e externas através da tecnologia, da Internet e dos novos meios de comunicação. O governo eletrônico tem assumido cada vez mais destaque pelo crescimento das expectativas dos cidadãos, globalização e progresso tecnológico e reforma do governo.

${ }^{3}$ Instituto Brasileiro de Geografia e Estatística-IBGE. (PNAD) Acesso à internet e à televisão e posso de telefone móvel celular para uso pessoal. Rio de Janeiro: IBGE, 2018.

${ }^{4}$ www.cetic.br.
}

\section{Referências}

DULCI, TOMÁS e XAVIER. Interfaces dos capitais humanos, cultural e social na situação ocupacional e nos rendimentos dos indivíduos. In: AGUIAR, N. (Org.). Desigualdades sociais, redes de sociabilidade e participação política. Belo Horizonte. Editora UFMG. 2007.

FÁVERO, Luiz Paulo et al. Análise de dados: modelagem multivariada para a tomada de decisões. Rio de Janeiro: Elsevier, 2009.

GUIDI, Leda. Democracia eletrônica em Bolonha: A rede Iperbole e a construção de uma comunidade participativa on-line. In: CEPIK, Marco e EISENBERG, José. Internet e Política. Belo Horizonte: Editora UFMG, 2002.

HAIR, J, Jr. Et. al. Análise multivariada de dados. Porto Alegre: Bookman, 2009.

Instituto Brasileiro de Geografia e Estatística-IBGE. (PNAD) Acesso à internet e à televisão e posso de telefone móvel celular para uso pessoal. $4^{\circ}$ trimestre de 2016 Rio de Janeiro: IBGE, 2018. 
LATTIN, James M. Análise de dados multivariados. São Paulo: Cengage Learning, 2011.

MAIA, Rousiley. Redes cívicas e Internet. Do ambiente informativo denso às condições da deliberação pública. In: CEPIK, Marco e EISENBERG, José. Internet e Política. Belo Horizonte: Editora UFMG, 2002.

MATIAS, V R S. O Phármakon da democracia eletrônica na gestão territorial urbana. Tese (doutorado) - Universidade Federal de Minas Gerais, Instituto de Geociências, 2011.

MATOS, Renata Assis de. Comparação de metodologias de análise de agrupamentos na presença de variáveis categóricas e contínuas; Dissertação (Mestrado em Estatística) - Programa de Pós- Graduação em Estatística, UFMG, Belo Horizonte, 2007.

MINGOTI, Sueli A. Análise de dados através de métodos de estatística multivariada: uma abordagem aplicada. $1^{\mathrm{a}}$ edição, $2^{\mathrm{a}}$ reimpressão. Editora UFMG. Belo Horizonte, 2013.

ROGERSON, Peter A. Métodos estatísticos para geografia: um guia para o estudante. Tradução técnica: Paulo Fernando Braga Carvalho e José Irineu Rangel Rigotti. Porto Alegre: Bookman, 2012.

SANTOS, Boaventura de Sousa. A gramática do tempo: para uma nova cultura política. $2^{\mathrm{a} e d}$. São Paulo: Cortez, 2008.

UHLIR, Paul F. Diretrizes políticas para o desenvolvimento e promoção da informação governamental de domínio público. Brasília: UNESCO, 2006. 